\title{
Estimation of lead in blood donors of Dakshina Kannada population in relation to smoking

\author{
Fathima Haneena $^{a}$, C.S. Muhammed Rashid ${ }^{a}$, A. Hashim ${ }^{b}$
}

aDepartment of RHCDC, Yenepoya Medical College Hospital, 'b Department of Forensic Medicine and Toxicology, Yenepoya University, Mangalore, Dakshina Karnataka, India

Correspondence to A. Hashim, MSc, Department of Forensic Medicine and Toxicology, Yenepoya Medical College, Yenepoya University, Derelakatte, Mangalore 575018, Karnataka, India Tel: +919742555052; e-mail: mhdhashim@gmail.com

Received 22 May 2018

Accepted 30 July 2018

The Egyptian Journal of Internal Medicine 2018, 30:212-216

\begin{abstract}
Introduction Methodology were obtained.

Results smokers but were in below toxic range ( $\sim 5 \mathrm{ppm})$.

Conclusion blood products if the lead levels are in toxic range.

\section{Keywords:}

atomic absorption spectrometer, blood donor, lead, smoker

Egypt J Intern Med 30:212-216

(c) 2019 The Egyptian Journal of Internal Medicine

1110-7782
\end{abstract}

Lead is a toxic heavy metal with hematotoxic, neurotoxic, and nephrotoxic effects even at low concentration. Presence of heavy metals like lead in the blood and blood products while donating blood can cause adverse effects to the recipients.

In this study, we have selected 130 volunteers from the donors list obtained from Yenepoya hospital and also from in and around Mangalore. Questionnaires was given to the volunteers to get information on smoking, passive smoking at home or at the work place, duration of smoking, occupation and health status. Whole blood samples were subjected to Atomic Absorption Spectrometer (AAS) and results

Lead content in smokers were found to be 2-3 times higher compared to non-

There are no present protocol to screen for heavy metals like lead in the blood banks. Our findings implicate the need to screen for heavy metals while transfusing blood to elderly people, neonates and infants and avoid transfusion of blood and

\section{Introduction}

Smoking tobacco is one of the common substance abuse worldwide and it is increasing in number day by day. Smoking cigarettes is one of the main causes for hypertension, diabetes, peripheral vascular disease, and cardiovascular disease, which constitutes a major cause for mortality and morbidity. Lead $(\mathrm{Pb})$ is a component of tobacco and tobacco products. It is a toxic heavy metal with hematotoxic, neurotoxic, and nephrotoxic effects even at low concentration. In infants and children it affects the learning abilities, and causes attention deficit disorder, aggressive and violent behaviour, hearing loss, convulsions, and mental retardation. In adults it may cause hypertension, ataxia, peripheral neuropathy, tremor, headache, loss of appetite, weight loss, fatigue, muscle, nephropathy, lead colic, and anemia. Lead enters the body through inhalation, swallowing, or absorbing lead particles. Once lead enters the body it is stored in the bones, blood, and tissues. The half-life of lead in blood is 28 days [Centre for Disease Control (CDC)] and in bones it is $\sim 20$ years. Smoking 20 cigarettes per day has been estimated to result in the inhalation of $1-5 \mu \mathrm{g} \mathrm{Pb}[1,2]$.

An analysis of blood samples collected from across the country has revealed that over $23 \%$ of the total samples tested positive with lead poisoning. So the selection of healthy donors is of significant importance from both a clinical and public health perspective. As there are significant number of donors who are tobacco smokers, it is difficult to exclude them from donating blood. Current guidelines on blood donation have focused on a number of factors that include infectious diseases, medical conditions, sexual preferences, and health-related behaviours, however, smoking is not mentioned. The measurements reported in the current paper revealed that in the smokers the blood concentration of $\mathrm{Pb}$ is higher than in their nonsmoking counterparts. By comparing $\mathrm{Pb}$ levels between the smoking and nonsmoking participants of our study, it is clearly evident that cigarette smoking creates an important source of chronic intoxication with these toxic metal. The half-life of lead in blood is 28 days (as per CDC guidelines), therefore to ensure safety while donating blood, smokers can be advised to stop smoking for a month before donating blood. Blood bank should screen the blood for heavy metals, such as lead while donating for neonates and infants as lead has more

This is an open access journal, and articles are distributed under the terms of the Creative Commons Attribution-NonCommercial-ShareAlike 4.0 License, which allows others to remix, tweak, and build upon the work non-commercially, as long as appropriate credit is given and the new creations are licensed under the identical terms. 
adverse effects even at lower levels in children than in adults.

\section{Participants and methods}

The study was conducted between the months of August 2017 to February 2018. An ethical clearance certificate was obtained from the Yenepoya University Ethics Committee, Mangalore, Karnataka to do work on human blood. So, 130 volunteers (65 smokers and 65 nonsmoker) from in and around Mangalore have been included in the study. The list of volunteers are obtained from the donors list available at the Yenepoya Medical College Hospital blood bank. The participants were contacted on telephone and were requested to come to the blood bank, Yenepoya Medical College Hospital, Mangalore for screening of the blood for lead. Informed consent was first taken from the participants by the PI or the Co PI. Semistructured questionnaire were given to the participants by the PI or Co PI and the responses were noted. Each participant was asked about the information on smoking, passive smoking at home or at the work place, occupation, and health status. Blood samples of $5 \mathrm{ml}$ were collected by venepuncture (antecubital vein) using disposable syringes and needles and standard aseptic precaution. EDTA $(1.5 \mathrm{mg} / \mathrm{ml}$ of blood) was used as an anticoagulant. It was a single blind study and the samples were coded. Only the principal investigator had the access to original data. Blood samples were immediately transferred to the RHCDC, Yenepoya Medical College Hospital and Sparsha Diagnostics Bendoor well, Mangalore on the same day; and stored between $4-7^{\circ} \mathrm{C}$ until the samples were taken for analysis. Samples were thawed prior to analysis, coagulation was prevented by this procedure. Collected samples were sent outside the institute (NITK Surathkal) for further analysis. All the samples were tested for lead using atomic absorption spectrometer. All these procedures were carried out under strict quality control conditions to avoid any contaminations. Special personal care was taken while handling the biological samples to prevent infection. Samples were destroyed after the study.

\section{Statistical analysis}

All statistical analyses were performed using SPSS software package (IBM SPSS statistics for Windows, version 22.0; IBM Corp., Armonk, New York, USA). Descriptive statistics of median and interquartile range were calculated. Mann-Whitney test was used to determine statistical significant difference in lead between smokers and nonsmokers. The duration of smoking was correlated with lead in smokers. $P$ less than 0.05 was considered statistically significant.

\section{Analysis of questionnaire}

To avoid confusion at the time of blood draw the volunteers were given a questionnaire prior to the procedure. Study variables included profession, place of living (urban/rural), smoking, and blood donation to identify potential factors related to serum $\mathrm{Pb}$ levels, and which aided in the analysis and interpretation of the results.

A semistructured questionnaire was prepared, including form and pertinence in relation to the objectives, with closed and open questions. All the interviews and blood collection were done from February 2018.

After appropriately coding the variables, a databank was prepared containing a dictionary with these codes and two additional spreadsheets with the first and second keying-in of the data. Validation consisted of a comparison of these two spreadsheets to check for inconsistences during feeding of the databank. The means of the serum $\mathrm{Pb}$ values were added to this databank, allowing cross-analysis of the information and appropriate statistical analyses

\section{Results}

The $\mathrm{Pb}$ concentration in the blood of smokers versus nonsmokers is presented in Tables 1 and 2. The blood $\mathrm{Pb}$ levels in smokers were higher by $1.21400 \mathrm{ppm}$ compared to the nonsmokers, that is, $0.40100 \mathrm{ppm}$ among the cigarette smokers.

There is a statistically significant correlation in $\mathrm{Pb}$ concentration in the blood of smokers and nonsmokers. There was no correlation between the duration of smoking and lead level $(\rho=0.003$, $P=0.982)$.

\section{Analysis of the questionnaire}

Response received from the participants for the number of cigarettes smoked by them showed 79\% smoked at least one every day.

Out of 65 participants 48 had smoked on the day of sample collection

\section{Discussion}

Lead is a class $2 \mathrm{~B}$ carcinogen and toxic to human, affecting the nervous system and neurodevelopment, particularly in children. Tobacco smoking is the world's most popular method of drug abuse. Smokers are indeed eligible to donate their blood, but there are certain risk factors present in such transfusion due to the presence of heavy metals. Blood donation is one of 
Table 1 Lead level in the blood

\begin{tabular}{|c|c|c|}
\hline \multirow[t]{2}{*}{ SI. No. } & \multicolumn{2}{|c|}{ Lead as $(\mathrm{Pb})$ in ppm } \\
\hline & Smoker & Nonsmoker \\
\hline 1 & 1.452 & 0.564 \\
\hline 2 & 1.269 & 0.489 \\
\hline 3 & 1.245 & 0.268 \\
\hline 4 & 1.561 & 0.478 \\
\hline 5 & 0.998 & 0.621 \\
\hline 6 & 1.124 & 0.542 \\
\hline 7 & 1.024 & 0.465 \\
\hline 8 & 1.154 & 0.265 \\
\hline 9 & 1.354 & 0.391 \\
\hline 10 & 1.356 & 0.412 \\
\hline 11 & 1.259 & 0.189 \\
\hline 12 & 1.445 & 0.215 \\
\hline 13 & 1.287 & 0.314 \\
\hline 14 & 1.069 & 0.428 \\
\hline 15 & 0.996 & 0.305 \\
\hline 16 & 1.465 & 0.546 \\
\hline 17 & 1.054 & 0.217 \\
\hline 18 & 1.182 & 0.401 \\
\hline 19 & 1.089 & 0.210 \\
\hline 20 & 0.986 & 0.542 \\
\hline 21 & 1.365 & 0.211 \\
\hline 22 & 1.234 & 0.316 \\
\hline 23 & 1.054 & 0.350 \\
\hline 24 & 1.216 & 0.198 \\
\hline 25 & 1.380 & 0.456 \\
\hline 26 & 1.099 & 0.521 \\
\hline 27 & 1.212 & 0.356 \\
\hline 28 & 1.092 & 0.746 \\
\hline 29 & 1.118 & 0.468 \\
\hline 30 & 1.201 & 0.560 \\
\hline 31 & 1.219 & 0.643 \\
\hline 32 & 1.305 & 0.243 \\
\hline 33 & 1.318 & 0.541 \\
\hline 34 & 1.144 & 0.624 \\
\hline 35 & 1.319 & 0.751 \\
\hline 36 & 1.201 & 0.350 \\
\hline 37 & 1.269 & 0.620 \\
\hline 38 & 1.168 & 0.435 \\
\hline 39 & 1.354 & 0.321 \\
\hline 40 & 1.206 & 0.254 \\
\hline 41 & 1.348 & 0.573 \\
\hline 42 & 1.046 & 0.354 \\
\hline 43 & 1.015 & 0.254 \\
\hline 44 & 1.724 & 0.641 \\
\hline 45 & 1.145 & 0.435 \\
\hline 46 & 1.108 & 0.346 \\
\hline 47 & 1.214 & 0.621 \\
\hline 48 & 1.206 & 0.245 \\
\hline 49 & 1.010 & 0.465 \\
\hline 50 & 1.189 & 0.552 \\
\hline 51 & 1.501 & 0.243 \\
\hline 52 & 1.249 & 0.334 \\
\hline 53 & 1.300 & 0.198 \\
\hline 54 & 1.267 & 0.246 \\
\hline 55 & 1.036 & 0.621 \\
\hline 56 & 1.355 & $\begin{array}{c}0.324 \\
\text { (Continued) }\end{array}$ \\
\hline
\end{tabular}

Table1 (Continued)

\begin{tabular}{lcc}
\hline SI. No. & \multicolumn{2}{c}{ Lead as $(\mathrm{Pb})$ in ppm } \\
\cline { 2 - 3 } & Smoker & Nonsmoker \\
\hline 57 & 1.246 & 0.295 \\
58 & 0.998 & 0.546 \\
59 & 1.211 & 0.238 \\
60 & 1.008 & 0.389 \\
61 & 1.227 & 0.824 \\
62 & 1.304 & 0.459 \\
63 & 1.331 & 0.398 \\
64 & 1.214 & 0.387 \\
65 & 1.065 & 0.521 \\
\hline
\end{tabular}

Table 2 Comparison of lead in smokers and nonsmokers blood samples

\begin{tabular}{lcccc}
\hline & $\begin{array}{c}\text { Lead as pb in } \\
\text { ppm smoker }\end{array}$ & $\begin{array}{c}\text { Lead as pb in } \\
\text { ppm } \\
\text { nonsmoker }\end{array}$ & $Z$ & $P$ \\
\hline Median & 1.21400 & 0.40100 & -9.837 & $\begin{array}{c}<0.001 \\
\text { (significance) }\end{array}$ \\
IQR & $(1.09550$, & $(0.28150$, & & \\
\hline
\end{tabular}

Median lead is higher in smokers compared to nonsmokers and it differed significantly $(P<0.001)$. IQR, interquartile range.

the most valuable contribution that a person can make towards the society. Blood transfusion is a critical part of neonatal intensive care and is life saving for neonates with severe anaemia and haemorrhage. Donors' blood is usually screened for some risk factors, such as hepatitis, HIV, and malarial parasite. It is not routinely screened for heavy metals, although its adverse effect on the human body is proved by a number of studies.

The current study provides data on the lead content in 130 blood samples obtained from the volunteers in and around Mangalore, Karnataka, India. Questionnaire and blood collection was done on the same day. Study variables included profession, place of living (urban/rural), smoking, and blood donation to identify potential factors related to serum $\mathrm{Pb}$ (lead) level. The levels of lead showed no difference in the participant's profession and place of living. Our study showed that $79 \%$ of the participants smoked at least one cigarette every day, and out of 65 participants 48 had smoked on the day of sample collection (Figs 1 and 2). There was no correlation between duration of smoking and lead level (Table 3).

The mean $\mathrm{Pb}$ level in blood samples of the nonsmokers was found to be $0.40100 \mathrm{ppm}$. Concentration in the nonsmokers was within the range of values reported by other authors [3-5] (Table 2). 
Figure 1

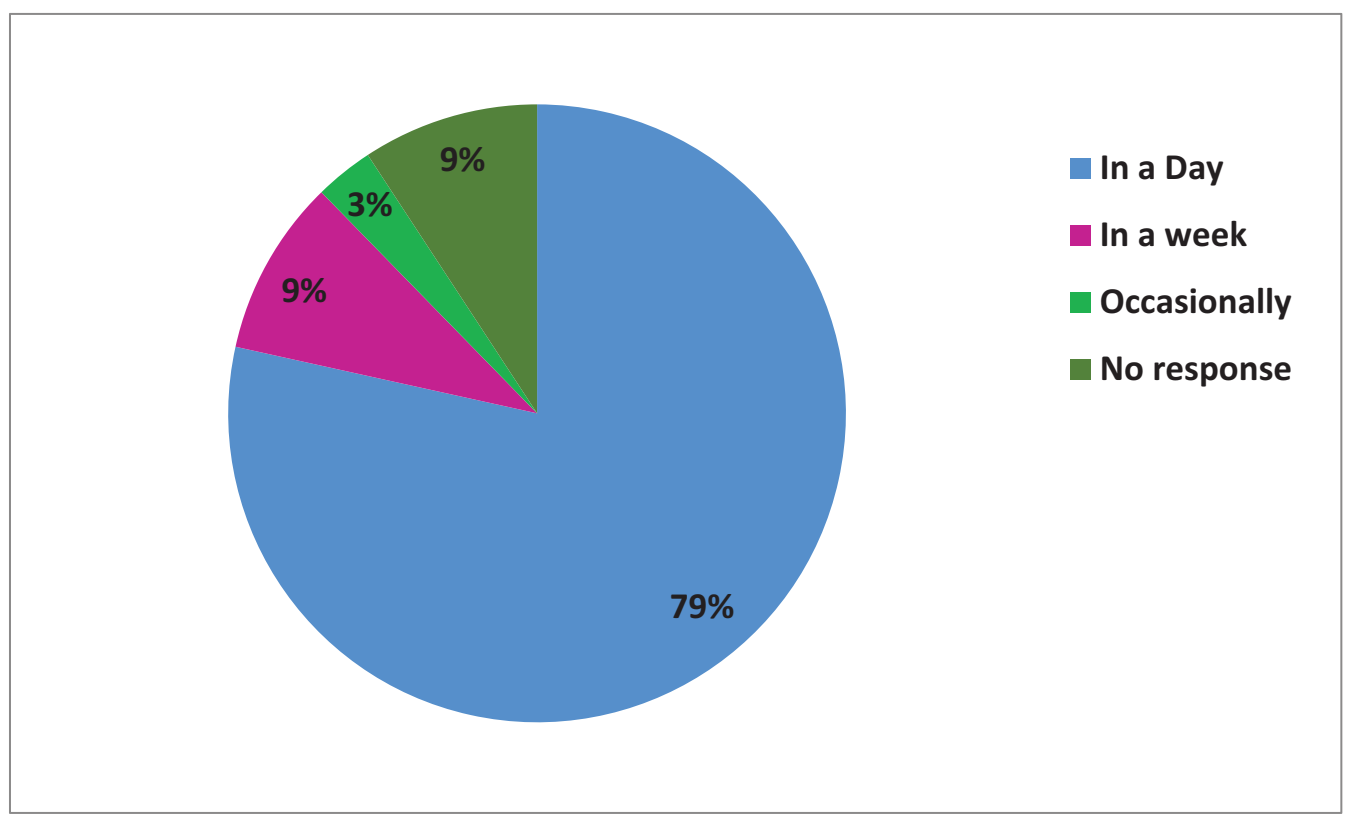

Percentage distribution of smoking.

Figure 2

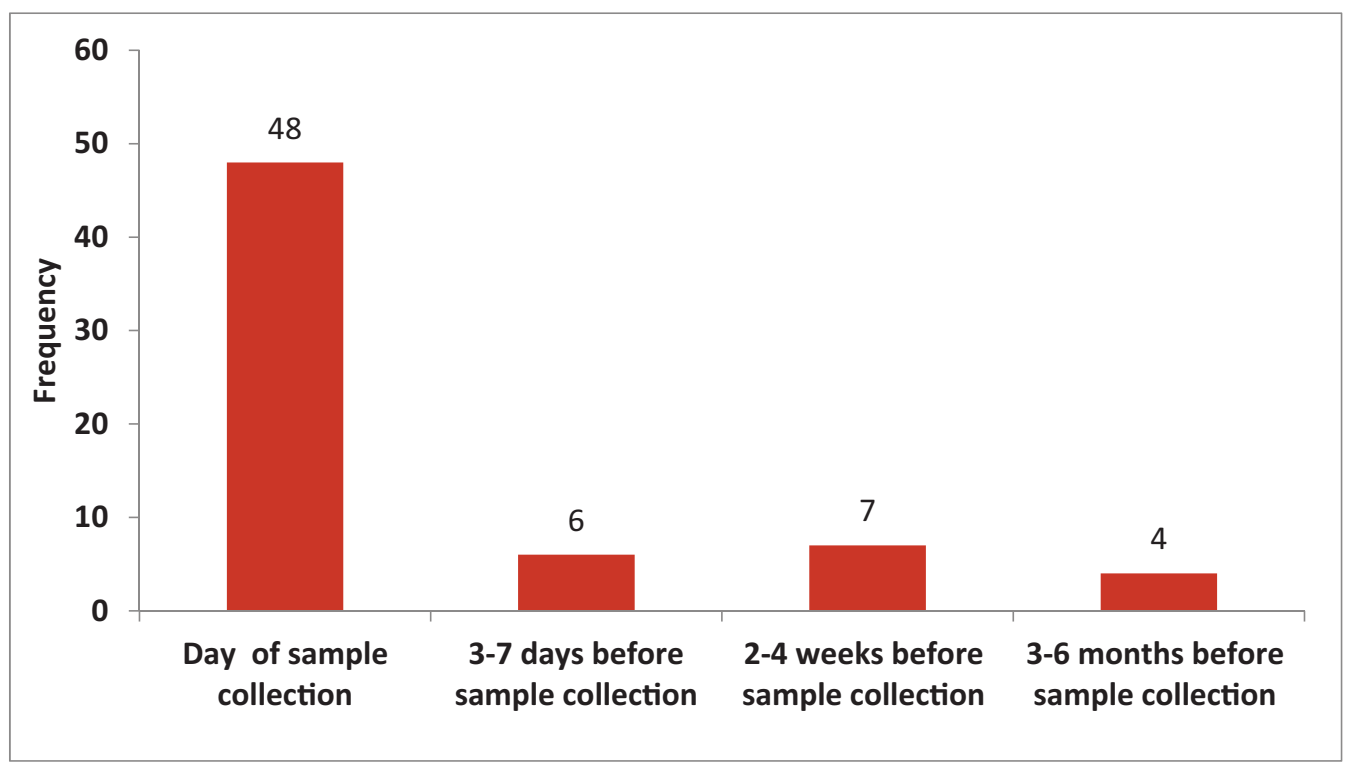

When was the last time smoked?

Table 3 Correlations between the duration of smoking and lead

\begin{tabular}{lccc}
\hline Spearman's & $\begin{array}{c}\text { Lead } \mathrm{as} \mathrm{Pb} \\
\text { in } \mathrm{ppm}\end{array}$ \\
$\rho$ & $\begin{array}{c}\text { Duration of } \\
\text { smoking months }\end{array}$ & $\begin{array}{c}\text { Correlation } \\
\text { coefficient }\end{array}$ & 0.003 \\
\hline & $P$ & 0.982 \\
& $N$ & 65 \\
\hline
\end{tabular}

There is no correlation between duration of smoking and lead $(\rho=0.003, P=0.982)$.
The blood $\mathrm{Pb}$ levels in smokers was higher by $1.21400 \mathrm{ppm}$ compared to the nonsmokers, that is, $\mathrm{Pb}$ levels is almost two to three times higher in smokers but it is within the normal range ( $5 \mathrm{ppm})$ as suggested by CDC (Tables 1 and 2).

Higher whole blood lead level of $10 \mu \mathrm{g} / \mathrm{dl}$ was also reported from previous studies [6]. Such samples have an additional risk if it used in infants for blood 
replacement. Heavy metal concentrations in donor's blood, which was designated for neonatal transfusion, was examined and it was found that some of the heavy metals including lead exceeded the estimated upper limit [7]. In a study of the lead exposure from blood transfusions in premature infants, it was found that blood products, such as packed red blood cells could actually double the lead concentration of the blood unit [8]. Male smokers have on an average slightly higher $\mathrm{PbB}$-levels than male nonsmokers [9]. High levels of $\mathrm{PbB}$ were also reported in the blood of 60-65 year-old residents of Cologne and two small cities near Cologne [10]. and in Dutch urban women ranged from 40 to $240 \mathrm{ppb}$ [11]. Smoking of 20 cigarettes a day has been estimated to result in the inhalation of $1-5 \mu \mathrm{g} \mathrm{Pb}$. The WHO estimates that $2-6 \%$ of $\mathrm{Pb}$ in cigarettes is inhaled by the smoker [1].

\section{Conclusion}

Blood transfusion is a life saving event. The selection of healthy donors is of significant importance, especially while transfusing blood to neonates and infants. Recipients of blood products are at risk of exposure to lead as there is no present protocol to screen for heavy metals in the blood banks. It is difficult to exclude smokers from donating blood, however our findings implicate the need to screen for heavy metals while transfusing blood to elderly people, neonates, and infants and avoid transfusion of blood and blood products if the lead levels are in toxic range (i.e. $\sim 5 \mathrm{ppm}$ ).

\section{Acknowledgment}

I am thankful to Shehin Muhammed, Dr. Leena K Promod, Mohammed Safwan Teaching and nonteaching staffs of Department of Forensic Medicine and Toxicology, Yenepoya Medical College, Mangalore, India for helping me in the preparation of this article.

\section{Financial support and sponsorship}

Nil.

\section{Conflicts of interest}

There are no conflicts of interest.

\section{References}

1 Ashraf MW. Levels of heavy metals in popular cigarette brands and exposure to these metals via smoking. Sci World J 2012; 2012:729430.

2 Järup L. Hazards of heavy metal contamination. Br Med Bull 2003; 68:167-182.

3 Bernhard D, Rossmann A, Wick G. Metals in cigarette smoke. IUBMB Live 2005; 57:805-809.

4 Popko J, Olszewski S, Hukałowicz K, Markiewicz R, Borawska MH, Szeparowicz P. Lead, cadmium, copper and zinc concentrations in blood and hair of mothers of children with locomotor system malformations. Pol J Environ Stud 2003; 12:375-379.

5 Baecklund M, Pedersen NL, Bjorkman L, Vahter M. Variation in blood concentrations of cadmium and lead in the elderly. Environ Res. 1999; 80:222-230.

6 Bulleora S, Manalo M. Lead levels in blood bank blood. Arch Environ Health $2001 ; 56: 312-313$.

7 Sundararajan S, Blatz AM, Dearborn DG, Varnes AW, Bearer CF, et al. Toxic metal contamination of banked blood designated for neonatal transfusion. J Clin Toxicol 2015; 5:267.

8 Duncan KJ, Reid H, Voutchkov M. Lead concentrations in Jamaican blood donors in relation to occupation. J Contin Educ Top Issues. 2010; 2010:116-118

9 Akinci I, Tutkun E, Turksoy VA, Yilmaz H, Yuksel B, Kayaalti Z, et al. Toxic metal and essential trace element levels of blood donors. J Clin Anal Med 2016; 7:816-819.

10 Brockhaus A, Freier I, Ewers U, Jermann E, Dolgner R. Levels of cadmium and lead in blood in relation to smoking, sex, occupation, and other factors in an adult population of the FRG. Int Arch Occup Environ Health 1983; 52:167-175.

11 Zielhuis RL, Stuik EJ, Herber RFM, Salle HJ, Verberk MM, Posma FD, et al. Smoking habits and levels of lead and cadmium in blood in urban women. Int Arch Occup Environ Heath 1977; 39:53. 